\title{
BIOMECHANICS ASPECTS OF TECHNIQUE OF HIGH JUMP
}

\author{
Adashevskiy V.M. ${ }^{1}$, Iermakov S.S. ${ }^{2}$, Marchenko A.A. ${ }^{1}$
}

National technical university "KPI"

Kharkov state academy of physical culture ${ }^{2}$

Annotation. The purpose of work consists in the theoretical ground of optimum biomechanics descriptions in high jumps. A mathematical model is developed for determination of influence on the height of jump: speed and corner of flight of centre-of-mass during pushing away, positions of centre-of-mass body of sportsman in the phases of pushing away and transition through a slat, forces of resistance of air environment, influences of moment of inertia of body. The basic technical run-time errors of sportsman are selected exercises. To biomechanics descriptions, to the step-up effectiveness of high jumps belong: speed of flight of centre-of-mass sportsman (4.2-5.8 meters in a second), corner of flight of centre-of-mass body (50-58 degrees), height of flight of centre-of-mass body (0.85-1.15 meter). Directions of choice of necessary biomechanics descriptions which a sportsman can realize are shown. Offered recommendation on the increase of effectiveness of high jumps.

Keywords: biomechanics, trajectory, pose, sportsman, jump, height.

\section{Introduction.}

Selection of optimal parameters, which predetermine successfulness of technical actions, is an important component of a sportsman movements' efficiency increasing. One of leading places in such movements is taken by bio mechanical aspects of technique and the possibility of its simulation on all stages of sportsman's training. The process of simulation, in its turn, demands considering both: general regularities of movement technique's building and sportsman's individual features. Such approach, to a large extent, promotes searching of technique optimal parameters and its realization on certain stages of a sportsman's training.

The works by N.A. Bernstein [3], V.M. Dyachkova [7], V.M. Zatsiorskiy [10], A.N. Laputina [4, 12], G. Dapena [18], P.A. Eisenman [20] are theoretical basis of sport movements bio mechanical regularities researches. The demand for preliminary simulating and further selecting of the most rational bio mechanical parameters of movements is mentioned in the works by V.M. Adashevskiy [1, 2, 28], S.S. Iermakov [8, 28], V.Ye. Chinko [14] et al.

The searching of sportsman jump kinematical and dynamic parameters' optimal combination [15-17], considering the regularities of mechanical energy transmission from link to link [18-20, 27] is of great importance. Such approach permits to successfully influence on the results of sport activity while executing high jumps [21, 25, 26]. With this it is recommended to apply mathematical patterns of movements [5-8, 23, 24], characteristics of sportsman's postures and movements [8].

Sports results of high jumps, to a large extent, are determined by rational bio mechanical characteristics, which a sportsman is able to realize, namely: speed of running, speed of repulsion, takeoff angle of a sportsman' body masses center, position of a sportsman's body masses center in the phases of repulsion and bar over passing.

Alongside with this, some of the above mentioned items concerning high jumps shall be specified.

So, I.V. Lazarev notes, that determination of "fosbury flop" on the stage of sportsmanship formation, revelation of repulsion structure and mechanism, development and application of jump patterns in training is one of urgent problems of running high jumpers training. Kinematical (takeoff height in unsupported phase, speed of running) and dynamic (repulsion impulse by vertical component, average repulsion force by vertical component, force in extremum) indicators effect on improvement of running "fosbury flop" high jumps results to the largest extent $[11,13]$.

G.A. Zaborskiy thinks that comparison of movements optimum pattern characteristics with really implemented jumper's repulsion movements structure will permit to find out such elements of his technical and speed-strength preparedness, whose correction and development will permit him to form individual optimal jump repulsion technique. [9].

And with that, the demand in researches for simulation of jump patterns for modern conditions of competition activity is still rather acute.

The researches were carried out as per governmental subject M0501 "Development of innovative methods and methods of diagnostics of different qualification and specialization sportsmen's main kinds of preparedness" 20122013.

Purpose, tasks, material and methods.

The purpose of the work: theoretical foundation of main rational bio-mechanical characteristics of high jumps and composing of recommendations for improvement of high jumps effectiveness.

The tasks of the work:

- analysis of special literature;

- building of pattern for determination of masses center's takeoff speed and angle at repulsion, position of sportsman's body masses center in repulsion and bar over passing phases, air resistance, moment of inertia influence on the height of jump;

- composing of recommendations for improvement of "fosbury flop" high jumps results. 
The subject of the researches: a sportsman's bio-mechanical characteristics, which promote improving of high jumps effectiveness.

The object of the researches: sportsmen of high qualification- high jumpers.

In solving of the problems special software complex "KIDIM", which was developed at NTU "KPI" department of theoretical mechanics, was used.

\section{Results of research.}

Sport results of high jumps are determined, mainly, by rational bio-mechanical characteristics, which a sportsman is able to realize, namely: running speed and, consequently, by speed and takeoff angle of sportsman's masses center, by position of the sportsman's masses center in repulsion and bar over passing phases. That is why, the necessity of fulfillment of all above enumerated bio-mechanical parameters in order to obtain maximal results of "fosbury flop" high jumps, is quite evident.

With this it is necessary to proceed from the following preconditions. Jump height is determined, mainly, by biomechanical characteristics, which a sportsman is able to realize, namely:

- running speed;

- speed of masses center takeoff at repulsion;

- angle of a sportsman masses center's takeoff at repulsion;

- position of a sportsman's masses center in repulsion and bar over passing phases;

Takeoff speed and angle of sportsman's masses center at repulsion are the main bio-mechanical characteristics of high jumps.

Speed of masses center takeoff at repulsion is a resulting speed, vertical and horizontal components of sportsman's speed of repulsion.

Male sportsmen of high class quality have horizontal running speed $6.5-8$ mps while resulting speed of masses center takeoff at repulsion is $4.5-5.4 \mathrm{mps}$.

The height of body masses center at repulsion depend on anthropometric parameters and kind of jump. With bar over passing body masses center can be higher than the bar (dumping) or lower (with "fosbury flop" jump), depending on the kind of jump.

The most rational angle of a sportsman masses center's takeoff at repulsion is chosen within 56-59 degrees to horizon considering air resistance force.

With rational combination of these bio-mechanical parameters, "fosbury-flop" jumps results are $2.2-2.4 \mathrm{~m}$.

Using the calculated diagram, let us consider the influence of vertical and horizontal speed components and takeoff angle of sportsman body's masses center on repulsion speed and, consequently, on takeoff speed of sportsman body's masses center (fg.1).

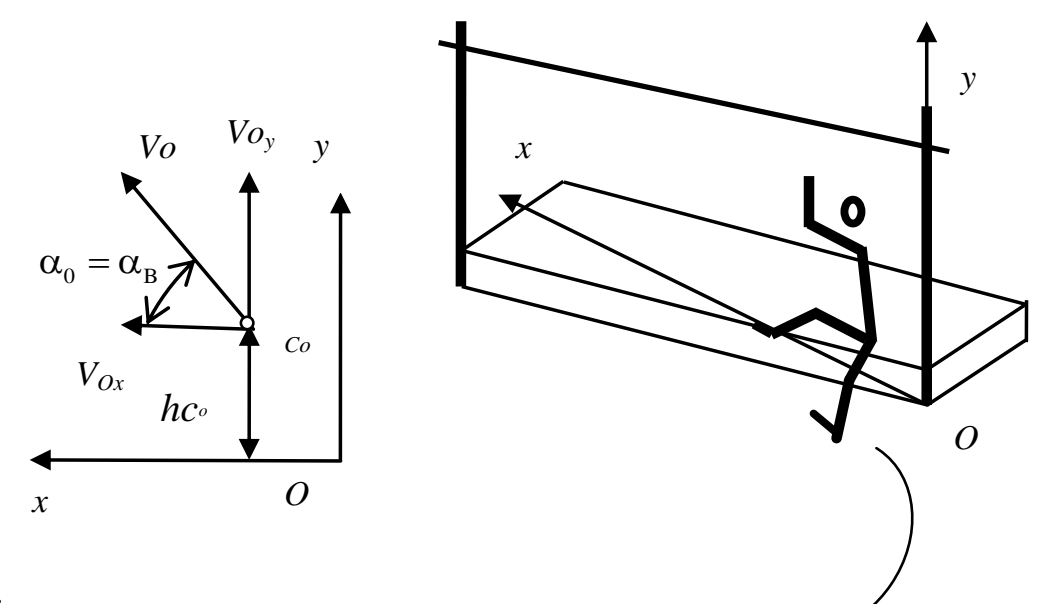

Fig.1. Calculated diagram for determination of repulsion parameters

$$
\vec{v}_{0}=\vec{v}=\vec{v}_{\Gamma}+\vec{v}_{\mathrm{B}}
$$

Here $\mathrm{V}_{0}$ initial repulsion (takeoff) speed of sportsman body's masses center,

$\mathrm{V}_{\mathrm{G}}=\mathrm{V}_{\mathrm{X}}$ - horizontal speed of body's running (horizontal component),

$\mathrm{V}_{\mathrm{B}}=\mathrm{V}_{\mathrm{Y}}-$ vertical component of repulsion speed,

$\mathrm{h}_{\mathrm{C} 0}$ - body masses center's height at repulsion,

$\alpha_{0}=\alpha_{B}-$ takeoff angle of sportsman's masses center at repulsion,

In projections to Cartesian absolute coordinates system this equation takes the form:

$$
v_{0 x}=\mathrm{v}_{\mathrm{G}} ; \quad v_{0 y}=\mathrm{v}_{\mathrm{B}} ; \quad v_{x}=v_{0} \cos \alpha ; \quad v_{y}=v_{0} \sin \alpha .
$$

Absolute initial takeoff speed is expressed as follows:

$$
v_{0}=\sqrt{v_{0 x}^{2}+v_{0 y}^{2}}
$$



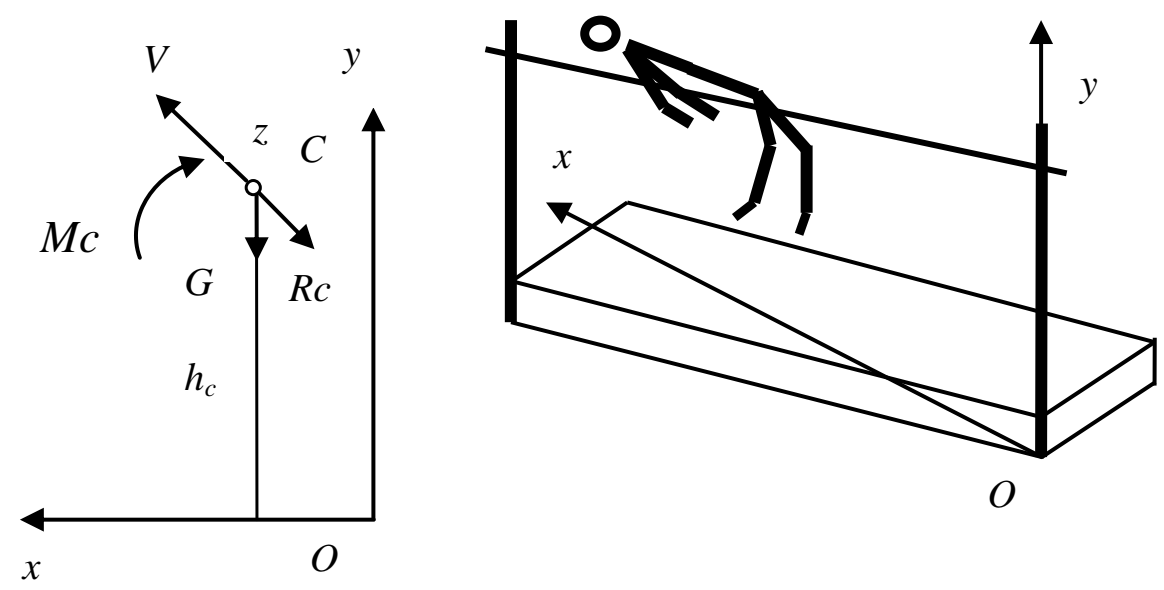

Fig.2. Calculated diagram for determination of rational bio-mechanical parameters in flight phase $\mathrm{G}$-gravity force, $\mathrm{Mc}$ - moment of air resistance forces, $\mathrm{h}_{\mathrm{C}}-$ current height of body masses center, $\mathrm{Rc}-$ air resistance force.

Air resistance force $R c$ for objects, moving in air of $\rho$ density equals to vector sum $\vec{R}_{c}=\vec{R}_{n}+\vec{R}_{\tau}$ of lifting force $R_{n}=0.5 c_{n} \rho s V^{2}$ and head resistance force $R_{\tau}=0.5 c_{\tau} \rho s V^{2}$. During calculation of these forces, non-dimensional coefficients $\left(c_{n}\right.$ and $\left.c_{\tau}\right)$ are determined experimentally depending on the shape of a body and its orientation in its environment. Value S (middle) is determined by the value body cross section's projection on the plane, which is perpendicular to the axis of movement, $\mathrm{V}-$ is absolute speed of body.

It is known that air density is $\rho=1,3 \mathrm{~kg} / \mathrm{m}^{3}$. It should be noted that body in flight has common free motion. Angle of body turns in anatomical planes change and with it, correspondingly, value $\mathrm{S}$ also changes. Determination of variable $\mathrm{S}$ middle values and head resistance coefficient $c_{\tau}$ require additional researches, that is why for solution of our task we take their averaged values.

Also, it is possible to determine average values of coefficient $(\kappa)$, which is near $\mathrm{V}^{2}-$ absolute speed of body flight in jump.

Without consideration of lifting force, which has very negligible, we obtain average values of the coefficient.

Then $R_{\tau}=R_{c}=k V^{2}$.

$$
k=0.5 c_{\tau} \rho s \quad k=0-1 \mathrm{~kg} / \mathrm{m} .
$$
plane.

Let us consider that sportsman's body moves in one of anatomical planes in flight phase. In our case it is sagittal

Let us compose dynamics equations of plane-parallel motion in projections on co-ordinates axes.

$$
m \ddot{x}_{c}=P_{x}^{e} ; \quad m \ddot{y}_{c}=P_{y}^{e} ; \quad J_{z} \ddot{\varphi}=M_{z}^{e} .
$$

Here $m$-body mass, $\ddot{X}_{c}, \ddot{Y}_{c}$ - correspond to projections of masses center acceleration, $P_{x}^{e}, P_{y}^{e}$ - projections of external forces, which affect on body, resultant, $J_{z}$ - moment of inertia in relation to front axis, $\ddot{\varphi}$ - corresponds to angle acceleration at body turn around front axis, $M_{z}^{e}$ - sum moment of external air resistance forces relating to front axis.

For movement in plane $x A y$, equation system can be expressed as follows:

$$
\begin{array}{cl}
m \ddot{x}=-R_{c_{X}} ; & m \ddot{y}=-G-R_{c_{Y}} J_{z} \ddot{\varphi}=-M_{c} \\
m \ddot{x}=-k v^{2} \cos \alpha ; \quad m \ddot{y}=-m g-k v^{2} \sin \alpha ; \quad J_{z} \ddot{\varphi}=-k \dot{\varphi}^{2} \\
\cos \alpha=\dot{x} / v ; \quad \sin \alpha=\dot{y} / v ; \quad v=\sqrt{v_{x}^{2}+v_{y}^{2}}=\sqrt{\dot{x}^{2}+\dot{y}^{2}}
\end{array}
$$

$\alpha$ - angle between current projections of body masses center speed and speed vector.

Solution of this task requires integrating of differential equations of motion.

Let us regard influence of sportsman body masses center's speed and angle, sportsman body masses center's position in repulsion phases, moment of inertia in regard to the front axis, considering air resistance forces. 


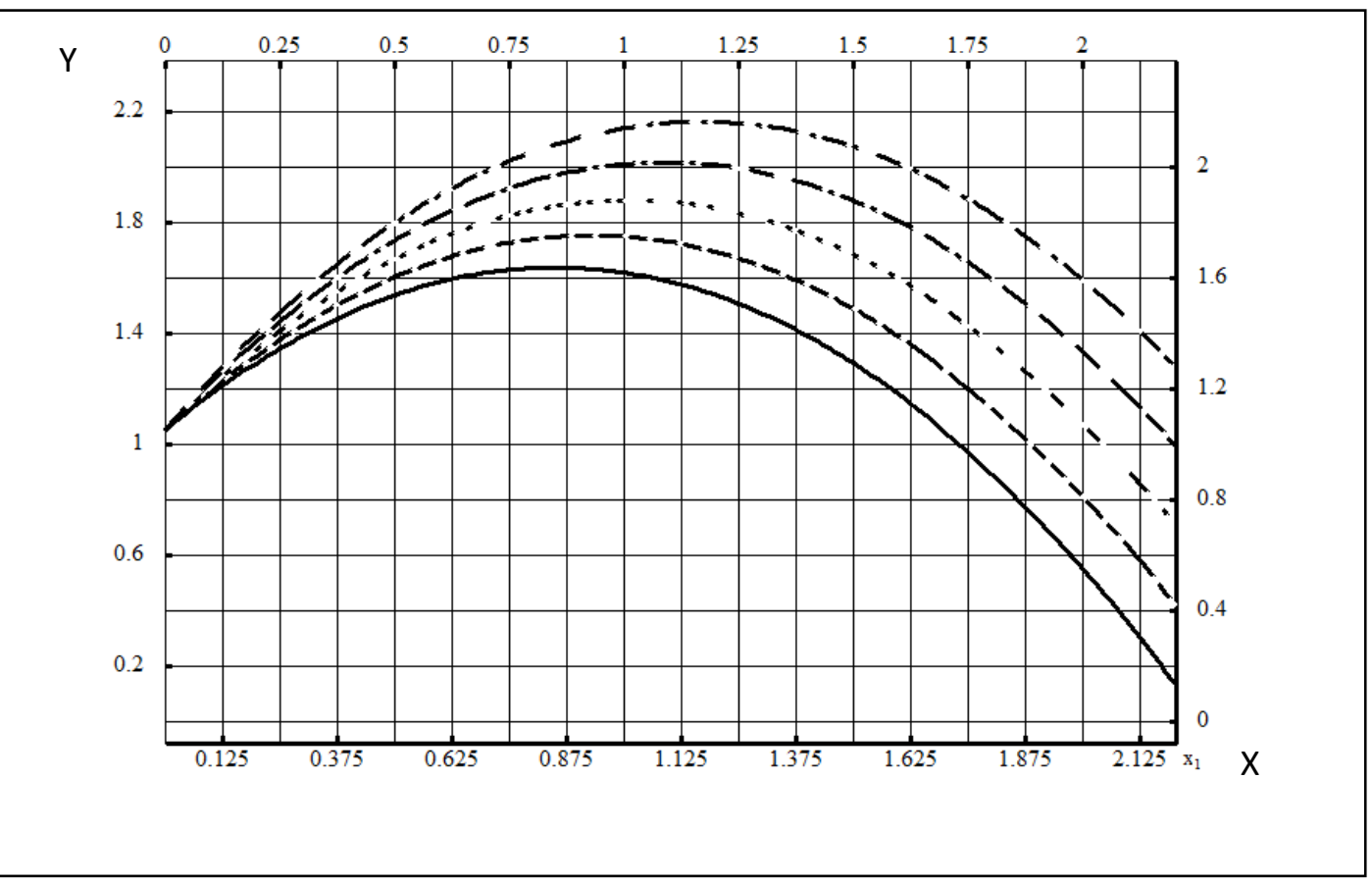

$-\cdot \mathrm{V}_{0}=5.8 \mathrm{mps} ;--\cdot \mathrm{V}_{0}=5.4 \mathrm{mps} ; \cdots . . \mathrm{V}_{0}=5.0 \mathrm{mps} ;--\mathrm{V}_{0}=4.6 \mathrm{mps} ;--\mathrm{V}_{0}=4.2 \mathrm{mps}$.

Fig.3. Characteristic curves of masses center trajectory for different values of takeoff initial speed

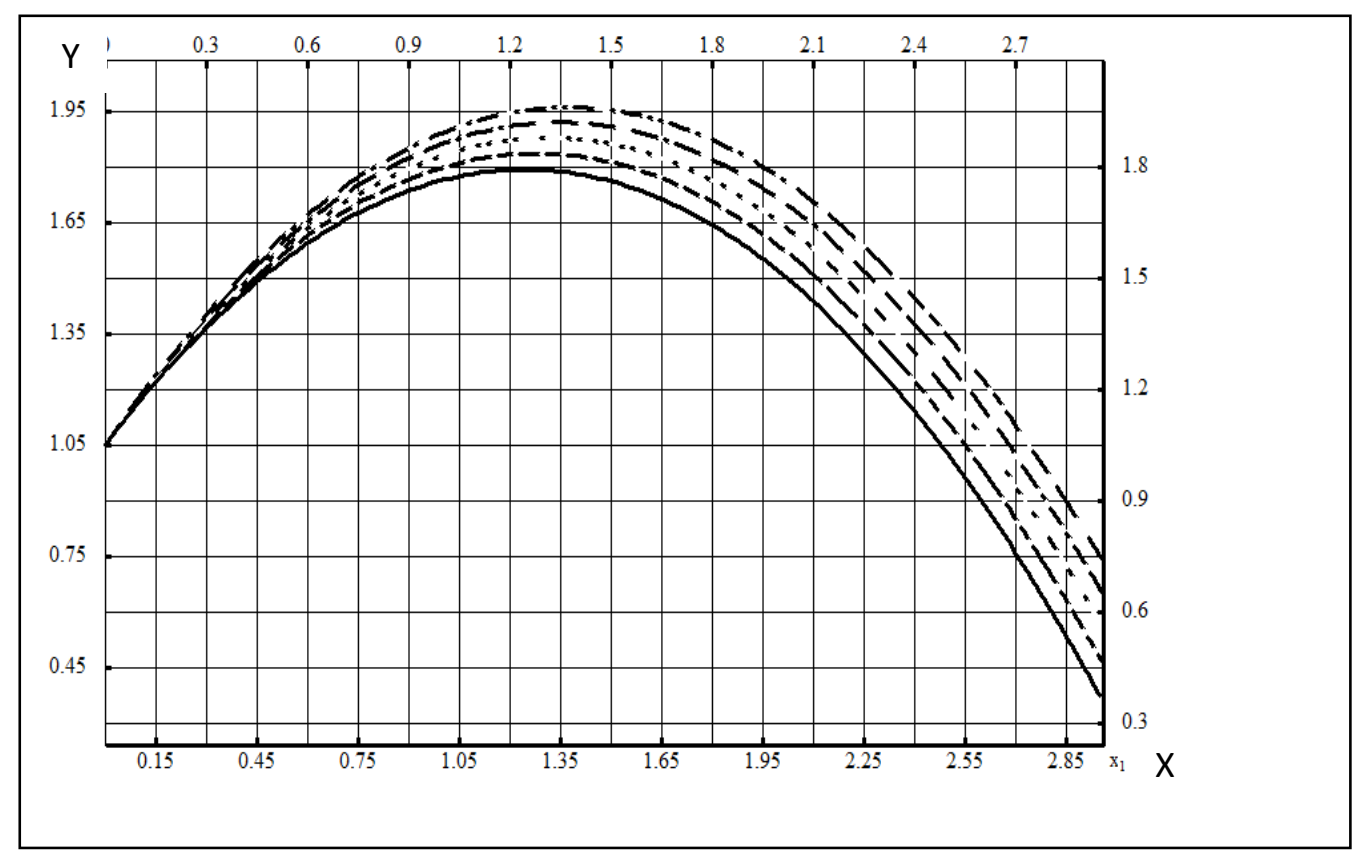

$-\cdot \alpha_{0}=58^{0} ;--\cdot \alpha_{0}=56^{0} ; \cdots \cdot \alpha_{0}=54^{0} ;--\alpha_{0}=52^{0} ;--\alpha_{0}=50^{0}$.

Fig.4. Characteristic curves of masses center trajectories for different values of takeoff angles

Results of calculations on mathematical models and obtained characteristic curves show:

- different values of body's moments of inertia, relating to front axis, in flight change angle speed value and, consequently, values of turns quantity $\mathrm{N}$, that, with rational postures, can promote quicker rotation around front axis when over passing bar;

- for actual speeds of sportsman's body flight, air resistance force for different middles affects negligibly on changing of result;

- for reaching high results it is necessary to increase horizontal running speed and, as a result, initial takeoff speed, takeoff angle of body masses center, body masses center height at repulsion with their rational combination. 
The obtained calculated bio-mechanical characteristics of high jump are the models and in practice they will be a little different.

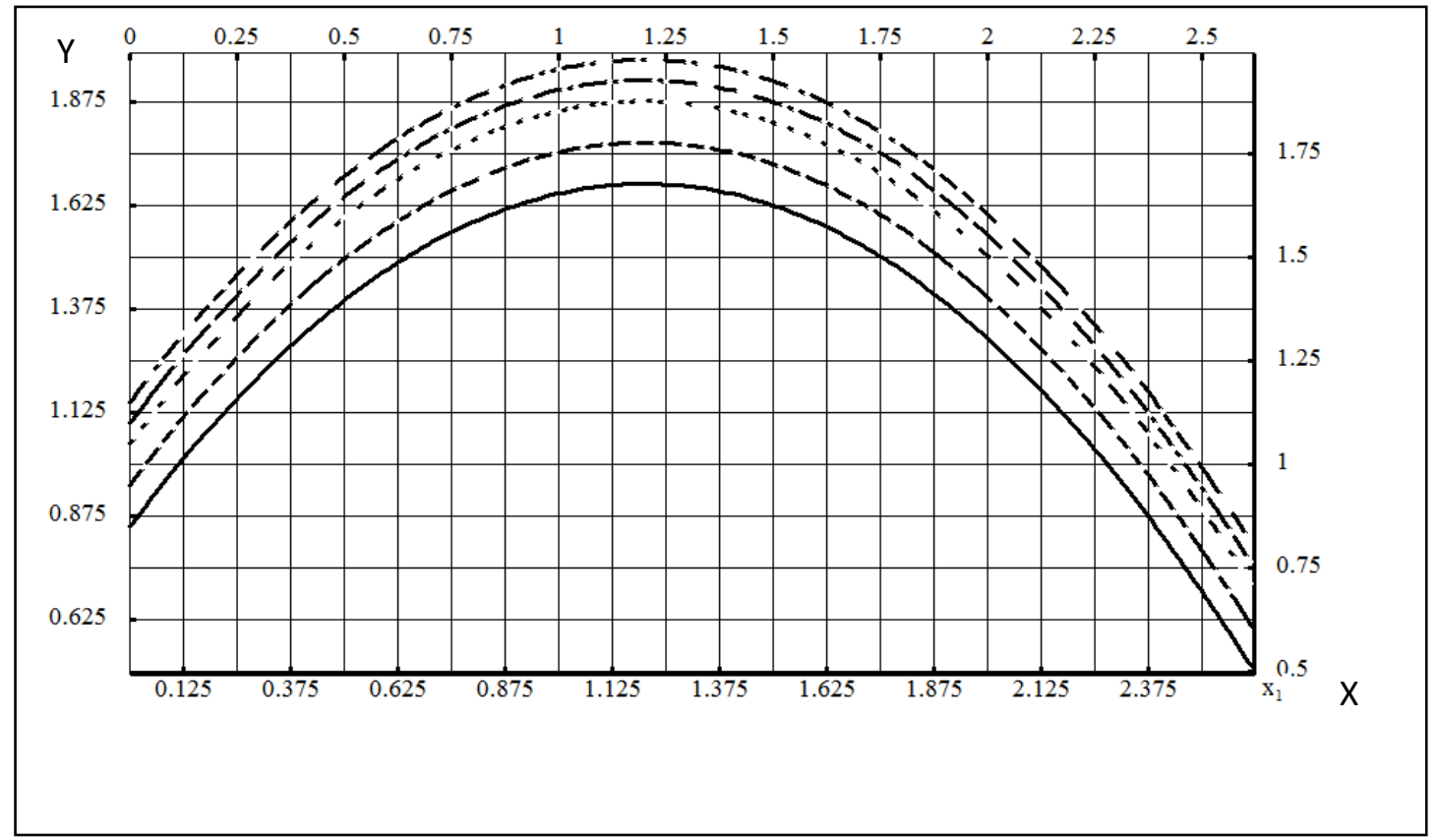

$-\cdot \mathrm{h}_{\mathrm{C} 0}=1.15 \mathrm{~m} ;--\cdot \mathrm{h}_{\mathrm{C} 0}=1.10 \mathrm{~m} ; \cdots \cdot \mathrm{h}_{\mathrm{C} 0}=1.05 \mathrm{~m} ;--\mathrm{h}_{\mathrm{C} 0}=0.95 \mathrm{~m} ;--\mathrm{h}_{\mathrm{C} 0}=0.85 \mathrm{~m}$.

Fig. 5. Characteristic curves of masses center trajectory for different body masses center height values

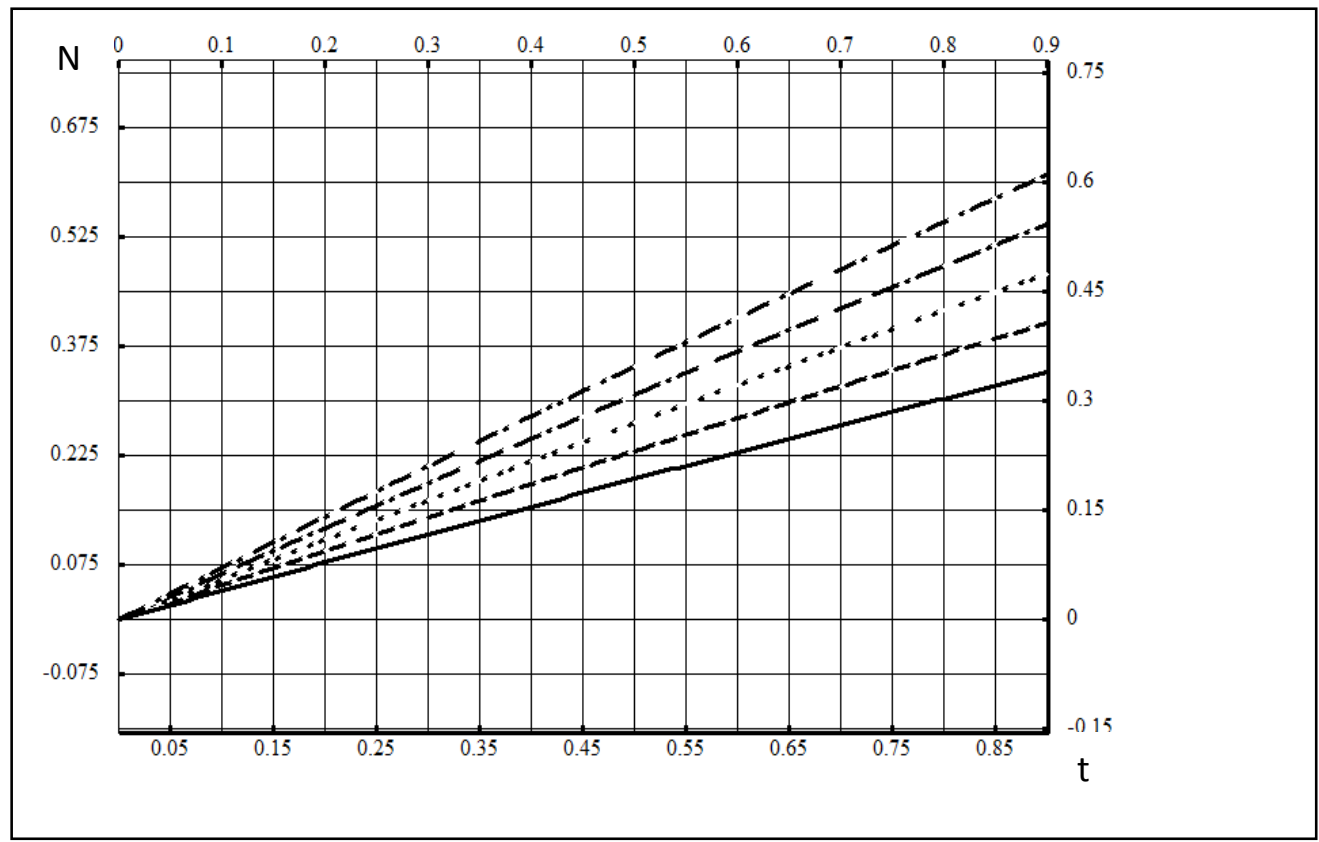

$-\cdot \mathrm{I}_{\mathrm{C}}=5 \mathrm{kgpm}^{2} ;--\cdot \mathrm{I}_{\mathrm{C}}=9 \mathrm{kgpm}^{2} ; \cdots \cdot \mathrm{I}_{\mathrm{C}}=13 \mathrm{kgpm}^{2} ;--\mathrm{I}_{\mathrm{C}}=17 \mathrm{kgpm}^{2} ;--\mathrm{I}_{\mathrm{C}}=21 \mathrm{kgpm}^{2}$.

Fig 6. Characteristic curves of quantity of turns for different moments of inertia relating to front axis

In researches of I.V. Lazarev the main indicators, which influences, to the largest extent, on improvement of running "fosbury flop" high jumps results [11]:

A) kinematical indicators:

- takeoff height in unsupported phase of jump 0,74 -0,98m;

- running speed $0,55 \mathrm{mps}$;

B) dynamic indicators:

- repulsion impulse by vertical component 0,67 - 0,73;

- average repulsion force by vertical component $0,70-0,85$;

- force in extremum $0,62-0,84$. 


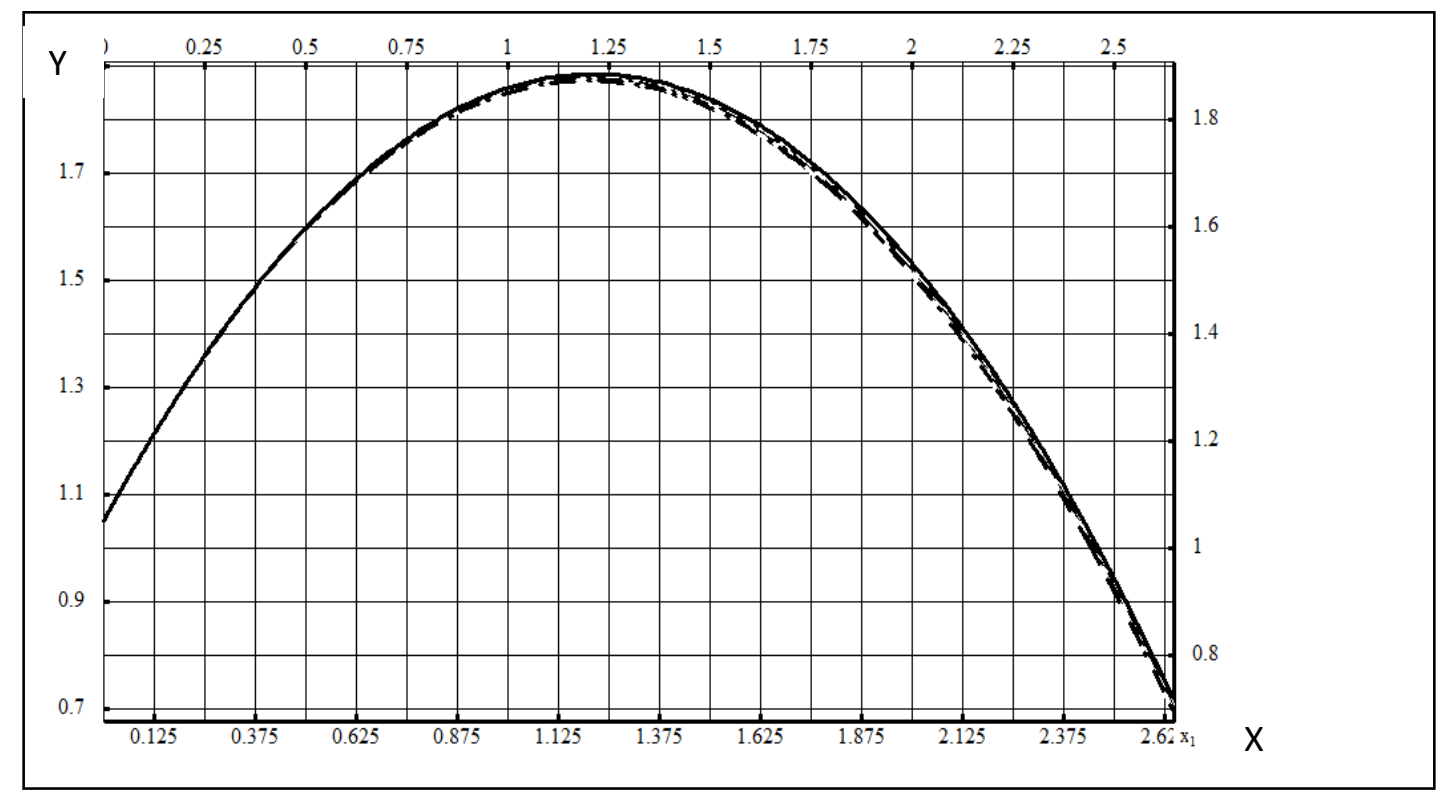

$-\cdot \mathrm{k}=1 \mathrm{kgpm} ;--\cdot \mathrm{k}=0.75 \mathrm{kgpm} ; \cdots \cdot \mathrm{k}=0.5 \mathrm{kgpm} ;--\mathrm{k}=0.25 \mathrm{kgpm} ;--\mathrm{k}=0 \mathrm{kgpm}$.

Fig. 7. Characteristic curves of masses center trajectory for different values of air resistance forces

Besides, it was established that the peculiarities of inner individual structure formation of qualified jumpers' technique are characterized, with increasing of sport results, by purposeful change of running speed, angle of leg position for repulsion, body's general masses center (g.m.c.) vertical movement way, body's g. m. c. takeoff angle. At repulsion it is necessary to pay special attention to foot position on rest with following, but not simultaneous, acceleration of waving links. Positioning of leg for repulsion shall be executed by active running movement from hip. Jumper shall carry out positioning of leg on full foot, with it the foot shall be located along the line of the running last step $[11,12]$.

G.A. Zaborskiy in his work stated that approaching of actual repulsion movement characteristics to theoretically optimal values is reached with increasing of masses center's angle of pitch above rest at starting the repulsion in condition of constant running speed. With this the portion of a sportsman's brake actions reduces in repulsion, while accelerated waving actions of body links, directly in repulsion phase, are activated due to the transfer of these movements' portion from buffering phase to the phase of repulsion [9].

\section{Summary}

Analysis of special literature showed that for ensuring of high jump's good result it is necessary to consider a number of many interconnected factors, which ensure maximal body flight height.

In general, high jumps sport results are determined by bio-mechanical characteristics, which a sportsman is able to realize, namely: running speed, sportsman body masses center's takeoff speed and angle, repulsion height of a sportsman's body masses center.

The following ranges of bio-mechanical characteristics increase the effectiveness of high jumps:

- $\quad$ sportsman's masses center's takeoff speed-4.2-5.8 m. p. s:

- $\quad$ sportsman's masses center's takeoff angle- $50^{0}-58^{0}$;

- $\quad$ sportsman's masses center's takeoff height $-0.85-1.15 \mathrm{~m}$.

It has been established that for achieving of high results it is necessary to increase horizontal running speed and, as a sequence, initial takeoff speed, body masses center's takeoff angle, body masses center's takeoff height at repulsion with their rational combination.

\section{References:}

1 Adashevskij V.M. Teoreticheskie osnovy mekhaniki biosistem [Theoretical basis of mechanics of biosystems], Kharkov, KPI Publ., 2001, 260 p.

2 Adashevs'kij V.M. Metrologiia u sporti [Metrology in sport], Kharkov, KPI Publ., 2010, 76 p.

3 Bernshtejn N.A. Ocherki po fiziologii dvizhenij i fiziologii aktivnosti [Essays on physiology of motions and physiology of activity], Moscow, Medicine, 1966, 349 p.

4 Laputin A.M. Biomekhanika sportu [Biomechanics of sport], Kiev, Olympic literature, 2001, 320 p.

5 Buslenko N.P. Modelirovanie slozhnykh sistem [Modeling of complex systems], Moscow, Science, 1988,400 p.

6 Dernova V.M. Voprosy fizicheskogo vospitaniia studentov [Questions of physical education of students], 1980, vol.14, pp. 50-54.

7 D'iachkov V.M. Pryzhok v vysotu s razbega [High jump from running approach], Moscow, Physical Culture and Sport, 1974, pp. 287-322. 
8 Iermakov S.S. Obuchenie tekhnike udarnykh dvizhenij v sportivnykh igrakh na osnove ikh komp'iuternykh modelej $i$ novykh trenazhernykh ustrojstv [Education to the technique of shock motions in sport games on the basis of their computer models and new trainer devices], Dokt. Diss., Kiev, 1997, 47 p.

9 Zaborskij G.A. Individualizaciia tekhniki ottalkivaniia u prygunov $v$ dlinu $i$ v vysotu s razbega na osnove modelirovaniia dvizhenij [Individualization of technique of pushing away for jumpers in length and in height from running on the basis of design of motions], Cand. Diss., Omsk, 2000, 157 p.

10 Zaciorskij V.M., Aurin A.S., Seluianov V.N. Biomekhanika dvigatel'nogo apparata cheloveka [Biomechanics of motive vehicle of a man], Moscow, Physical Culture and Sport, 1981, 143 p.

11 Lazarev I.V. Struktura tekhniki pryzhkov v vysotu s razbega sposobom Fosberi-Flop [Structure of technique of high jumps from running by means of Fosbury Flop], Cand. Diss., Moscow, 1983, 20 p.

12 Laputin A.N. Obuchenie sportivnym dvizheniiam [Education to sport motions], Kiev, Health, 1986, 216 p.

13 Mikhajlov N.G., Iakunin H.A., Lazarev I.V. Teoriia i praktika fizicheskoj kul'tury [Theory and practice of physical culture], 1981, vol.2, pp. 9-11.

14 Chinko V.E. Osobennosti tekhnicheskoj podgotovki prygunov v vysotu s razbega [Features of technical preparation of high jumpers from running], Cand. Diss., Leningrad, 1982, $26 \mathrm{p}$.

15 Athanasios Vanezis, Adrian Lees. A biomechanical analysis of good and poor performers of the vertical jump. Ergonomics, 2005, vol.48(11-14), pp. 1594 - 1603.

16 Aura O., Viitasalo J.T. Biomechanical characteristics of jumping. International Journal of Sports Biomechanics, 1989, vol.5, pp. 89-98.

17 Canavan P.K., Garrett G.E., Armstrong L.E. Kinematic and kinetic relationships between an olympic style lift and the vertical jump. Journal of Strength and Conditioning Research, 1996, vol.10, pp. 127-130.

18 Dapena G. Mechanics of Translation in the Fosbury Flop. Medicine and Science in Sports and Exercise, 1980, vol. 12, №1, p.p.37 44.

19 Duda Georg N., Taylor William R., Winkler Tobias, Matziolis Georg, Heller Markus O., Haas Norbert P., Perka Carsten, Schaser Klaus-D. Biomechanical, Microvascular, and Cellular Factors Promote Muscle and Bone Regeneration. Exercise \& Sport Sciences Reviews. 2008, vol.36(2), pp. 64-70. doi: 10.1097/JES.0b013e318168eb88

20 Eisenman P.A. The influence of initial strength levels on responses to vertical jump training. Journal of Sports Medicine and Physical Fitness. 1978, vol.18, pp. 227 - 282.

21 Fukashiro S., Komi P.V. Joint moment and mechanical flow of the lower limb during vertical jump. International Journal of Sport Medicine, 1987, vol.8, pp. 15 - 21.

22 Harman E.A., Rosenstein M.T., Frykman P.N., Rosenstein R.M. The effects of arms and countermovement on vertical jumping. Medicine and Science in Sports and Exercise, 1990, vol.22, pp. 825 - 833.

23 Hay James G. Biomechanical Aspects of Jumping. Exercise \& Sport Sciences Reviews. 1975, vol.3(1), pp. 135-162.

24 Lees A., Van Renterghem J., De Clercq D., Understanding how an arm swing enhances performance in the vertical jump. Journal of Biomechanics, 2004, vol.37, pp. 1929 - 1940.

$25 \mathrm{Li}$ Li. How Can Sport Biomechanics Contribute to the Advance of World Record and Best Athletic Performance? Measurement in Physical Education and Exercise Science. 2012, vol.16(3), pp. 194-202.

26 Paasuke M., Ereline J., Gapeyeva H. Knee extension strength and vertical jumping performance in Nordic combined athletes. Journal of Sports Medicine and Physical Fitness. 2001, vol.41, pp. 354 - 361

27 Stefanyshyn D.J., Nigg B.M. Contribution of the lower extremity joints to mechanical energy in running vertical jumps and running long jumps. Journal of Sports Sciences, 1998, vol.16, pp. 177-186.

28 Volodymyr Adashevsky, Sergii Iermakov, Krzystof Prusik, Katarzyna Prusik, Karol Gorner. Biomechanics: theory and practice. Gdansk, Zdrowie-Projekt, 2012, 184 p.

Information about the authors:

Adashevskiy V.M.: adashevsky@ukr.net; National Technical University “KPI”; Frunze str. 21, Kharkov, 61002, Ukraine.

Iermakov S.S.: sportart@gmail.com; Kharkov State Academy of Physical Culture; Klochkovskaya str. 99, Kharkov, 61022, Ukraine.

Marchenko A.A.: adashevsky@ukr.net; National Technical University “KPI”; Frunze str. 21, Kharkov, 61002, Ukraine.

Cite this article as: Adashevskiy V.M., Iermakov S.S., Marchenko A.A. Biomechanics aspects of technique of high jump. Physical Education of Students, 2013, vol.2, pp. 11-17. doi:10.6084/m9.figshare. 156374

The electronic version of this article is the complete one and can be found online at: http://www.sportedu.org.ua/html/arhive-e.html

This is an Open Access article distributed under the terms of the Creative Commons Attribution License, which permits unrestricted use, distribution, and reproduction in any medium, provided the original work is properly cited (http://creativecommons.org/licenses/by/3.0/deed.en). 